\title{
Unsaturated Hydraulic Conductivity of Compacted Bentonite: Revisit of Microstructure Effects
}

DOI:

10.1007/978-981-13-2224-2_67

Link to publication record in Manchester Research Explorer

\section{Citation for published version (APA):}

Chen, T., Sedighi, M., Jivkov, A., \& Seetharam, S. C. (2019). Unsaturated Hydraulic Conductivity of Compacted Bentonite: Revisit of Microstructure Effects. In L. Zhan, Y. Chen, \& A. Bouazza (Eds.), Proceedings of the 8th International Congress on Environmental Geotechnics. ICEG 2018 (Vol. 2, pp. 544-550). Springer Nature. https://doi.org/10.1007/978-981-13-2224-2_67

Published in:

Proceedings of the 8th International Congress on Environmental Geotechnics. ICEG 2018

\section{Citing this paper}

Please note that where the full-text provided on Manchester Research Explorer is the Author Accepted Manuscript or Proof version this may differ from the final Published version. If citing, it is advised that you check and use the publisher's definitive version.

\section{General rights}

Copyright and moral rights for the publications made accessible in the Research Explorer are retained by the authors and/or other copyright owners and it is a condition of accessing publications that users recognise and abide by the legal requirements associated with these rights.

\section{Takedown policy}

If you believe that this document breaches copyright please refer to the University of Manchester's Takedown Procedures [http://man.ac.uk/04Y6Bo] or contact uml.scholarlycommunications@manchester.ac.uk providing relevant details, so we can investigate your claim.

\section{OPEN ACCESS}




\title{
Unsaturated Hydraulic Conductivity of Compacted Bentonite: Revisit of Microstructure Effects
}

\author{
Tian Chen ${ }^{1}$, Majid Sedighi ${ }^{1(凶)}$, Andrey Jivkov ${ }^{1}$, \\ and Suresh C. Seetharam ${ }^{2}$ \\ ${ }^{1}$ School of Mechanical, Aerospace and Civil Engineering, \\ The University of Manchester, Manchester M13 9PL, UK \\ majid. sedighi@manchester.ac.uk \\ 2 Engineered and Geosystems Analysis Unit, Belgian Nuclear Research Centre, \\ SCK-CEN, 2400 Mol, Belgium
}

\begin{abstract}
Developing a sound theoretical description for the evolution of unsaturated hydraulic conductivity of compacted bentonite during re-saturation has remained a challenge because of the complex microstructure effects influenced by physico-chemical phenomena. This paper proposes a new relationship for the unsaturated hydraulic conductivity of compacted bentonite based on Kozeny-Carman relationship. A new relationship is also proposed for the relative permeability of compacted bentonite that incorporates the effects of microstructure swelling. The application of the new relationship for the case of compacted GMZ bentonite provides well correlated results with the experimental data reported in the literature.
\end{abstract}

Keywords: Compacted bentonite $\cdot$ Clay microstructure $\cdot$ Unsaturated Permeability

\section{Introduction}

In the context of geological disposal concepts for high level nuclear waste in crystalline rock, partially saturated compacted bentonite is to be emplaced in the depositional holes as buffer material. The clay buffer will undergo a re-saturation phase due to moisture intrusion from the host rock. Experimental observations have shown that the moisture flow and chemical transport in smectite rich clays are strongly influenced by swelling/shrinkage of the clay microstructure (Pusch and Yong 2006). The application of conventional unsaturated hydraulic conductivity relationships in predicting the moisture flow and chemical transport processes in compacted bentonite might overestimate the rate of re-saturation or chloride transport against the experimental observations (e.g. Sedighi et al. 2012; 2018). Limited experimental and theoretical approaches exist that can provide a sound description of the evolution of unsaturated hydraulic conductivity of compacted bentonite.

In this paper, various phenomenological aspects of microstructure of compacted bentonite and its evolution during wetting process are re-visited to develop a theoretical 
description of pore system. The established Kozeny-Carman relationship (Carman 1939; Kozeny 1927) for permeability of porous media is adopted and modified to describe the intrinsic permeability of compacted bentonite under confined conditions. A relationship for the relative permeability of compacted bentonite is proposed by incorporating the effects of swelling/shrinkage of the clay microstructure. The relationship proposed for the hydraulic conductivity of compacted bentonite is tested against a series of experimental results from the literature.

\section{Microstructure Evolution in Compacted Bentonite}

The pore system of compacted bentonite can be described by two scales of porosity: (i) micro porosity that includes the spaces between the unit layers of smectite (microstructure) and (ii) macro porosity that represents the pore spaces between the particles and aggregates of particles (Fig. 1). Macro/meso pores are the only major water conduits. Water molecules are exchanged between the micro and macro/meso pores. The water in micro pores has different properties compared with free water and is widely considered as an immobile phase (Sedighi and Thomas 2014). The interlayer hydration or dehydration process can only alter the distance between the clay microstructure units (interlayer distance) by adding or removing discrete layers of water in micro-porosity. During wetting/re-saturation, the size of micro porosity increases as the results of adsorption of water molecules into the interlayer space. Consequently, under confined conditions (i.e. swelling is constrained), the macro porosity can shrink, thus reducing the space for water to flow. By increasing the water content in smectite, the number of unit layers in a particle consistently decreases and the larger aggregates are divided into smaller particles (Saiyouri et al. 2004) that affects the tortuosity of the porous system. Figure 1 presents a schematic diagram of the evolution of pore system in compacted bentonite during re-saturation at constant total volume.

The volume of interlayer water can be described as:

$$
V_{I L}=d_{I L} N A_{s}
$$

where, $d_{I L}$ is the thickness of interlayer water (i.e. interlayer distance), $N$ stands for the total number of unit layer of smectite (TOT) in the sample and $A_{s}$ is the surface area of a TOT.

The thickness of interlayer water varies with water content due to adsorption of one to three layers of water in the interlayer space. The variations of interlayer water with the total volumetric water content follow a hydrodynamic adsorption behaviour that can be simplified by a quasi-dynamic equation (Azizian 2004), given as:

$$
d_{I L}=d-d_{0}=9\left[1-\exp \left(b \theta_{l}\right)\right]
$$

where, $d$ and $d_{0}$ is the basal spacing and thickness of single TOT sheet, respectively. $b$ is a constant that is related to the water adsorption isotherm of smectite $(b=-2.63$ 
Particles

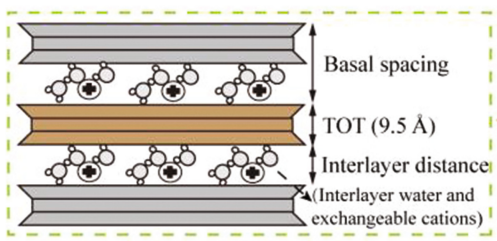

Partly saturated

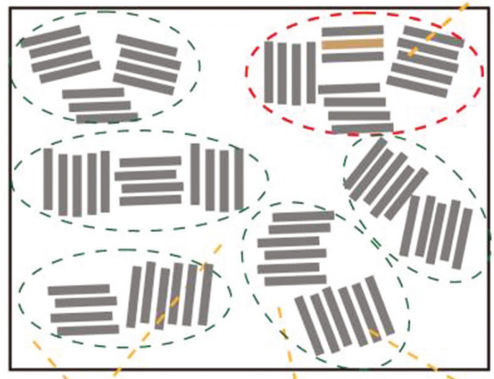

Macro porosity between the aggregates between the particles
Aggregates

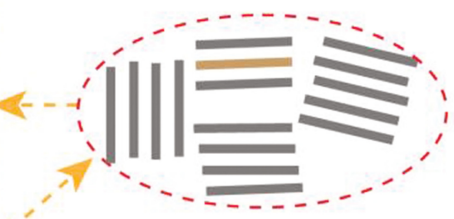

Fully saturated

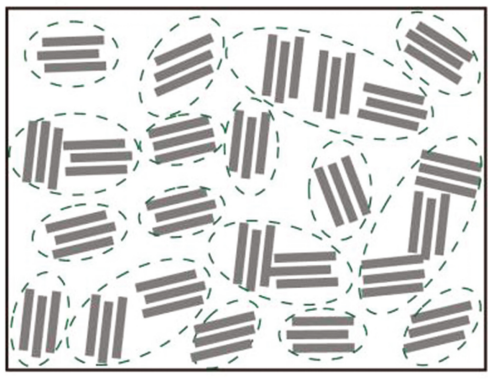

Micro porosity between the layers/sheets

Fig. 1. Schematic diagram of pore system evolution of compacted bentonite during wetting.

provides a good agreement with water/vapour adsorption data of smectite (Holmboe et al. 2012; Villar et al. 2012). $\theta_{l}$ is the total volumetric water content.

The total number of TOT layers in a sample $(N)$ can be given as:

$$
N=\frac{m_{\text {smectite }}}{m_{s}} n_{c}
$$

where, $m_{\text {smectite }}$ is the total mass of smectite in the soil, $m_{s}$ is the mass of single particle containing the number of $n_{c}$ TOTs and $n_{c}$ is the number of stacked TOT layers per particle that varies with water content (Saiyouri et al. 2004).

The surface area of a TOT $\left(A_{s}\right)$ can be calculated from the total specific surface area $\left(A_{\text {total }}\right)$ and mass of smectite $\left(m_{\text {smectite }}\right)$ in the soil:

$$
A_{s}=\frac{m_{\text {smectite }} A_{\text {total }}}{2 N}
$$

where, $A_{\text {total }}$ is the total specific surface area.

The micro porosity $\left(\phi_{\text {micro }}\right)$ and macro porosity $\left(\phi_{\text {macro }}\right)$ can therefore be calculated as:

$$
\begin{gathered}
\phi_{\text {micro }}=0.5 d_{I L} A_{\text {total }} \rho_{d}^{s} \\
\phi_{\text {macro }}=\phi_{t}-\phi_{\text {micro }}
\end{gathered}
$$

where, $\rho_{d}^{s}$ is the dry density of smectite in the soil and $\phi_{t}$ is the total porosity 


\section{Saturated Hydraulic Conductivity of Compacted Bentonite}

Kozeny-Carman relationship (KC) is an established theoretical approach that provides a relationship between porosity and permeability in porous media (Carman 1939; Kozeny 1927). However, it has been shown that the KC for compacted clays does not provide a good correlation with experimental observations (Chapuis and Aubertin 2003). The hypothesis presented here is that since part of the pore water in smectite is adsorbed in the microstructure and it is regarded as an immobile phase, the system of compacted bentonite should then be conceptualised by a dual porosity system, in which only the macro porosity contributes to the flow. Accordingly, the total porosity in $\mathrm{KC}$ relationship should be replaced by the macro porosity to provide a realistic pore system of compacted bentonite.

A modified Kozeny-Carman relationship for saturated hydraulic conductivity of compacted bentonite is therefore proposed that reflects the effects of microstructure on flow behaviour through the use of macro porosity in the relationship:

$$
k_{s a t}=\left(\frac{\gamma_{w}}{\mu_{w}}\right)\left(\frac{C_{s}}{\rho_{d}^{2} \tau^{2} A_{\text {ext }}^{2}}\right) \frac{\phi_{\text {macro }}^{3}}{\left(1-\phi_{\text {macro }}\right)^{2}}
$$

where, $\gamma_{w}$ and $\mu_{w}$ are the unit weight and viscosity of water, respectively. $C_{s}$ is a shape factor. $\rho_{d}$ is the dry density of soil. $\tau$ is the tortuosity and $A_{e x t}$ is the external specific surface area (i.e. $A_{\text {ext }}=A_{\text {total }} / n_{c}$ ).

\section{Unsaturated Hydraulic Conductivity of Compacted Bentonite}

The unsaturated hydraulic conductivity of compacted bentonite can be presented as a function of its saturated hydraulic conductivity (Mualem 1976), given as:

$$
k_{\text {unsat }}=k_{r} k_{\text {sat }}
$$

where, $k_{r}$ is the relative permeability that is commonly described as a function of water content (Mualem 1976):

$$
k_{r}=\left(\frac{\theta_{l}-\theta_{r}}{\theta_{\text {sat }}-\theta_{r}}\right)^{\alpha}
$$

where, $\theta_{\text {sat }}$ and $\theta_{r}$ are the saturated and residual volumetric water contents, respectively. $\alpha$ is a constant parameter. $\theta_{r}$ is calculated from the relationships between water content and suction based on experimental water/vapour adsorption data.

The relative permeability relationships are mainly based on observations and measurements in coarse grained soils where the entire porosity is available for water flow. However, in the case of compacted bentonite a considerable proportion of water 
is located in micro porosity, which is almost immobile. To account for this, a revised relationship for relative permeability is proposed as follows:

$$
k_{r}=\left(\frac{\theta_{\text {macro }}-\theta_{\text {macro }, r}}{\phi_{\text {macro }}-\theta_{\text {macro }, r}}\right)^{\alpha}
$$

where, $\theta_{\text {macro }}$ is the volumetric water content in macro porosity and $\theta_{\text {macro, } r}$ is the residual macro water content. The value of $\theta_{\text {macro }}$ is calculated from $\phi_{\text {micro }}$ (Eq. 5) and total volumetric water content $\left(\theta_{l}\right)$ at a given soil water potential or suction $\left(\theta_{\text {macro }}=\theta_{l}-\phi_{\text {micro }}\right)$.

\section{Application to Compacted GMZ Bentonite}

The relationship proposed for hydraulic conductivity is applied for the case of GMZ bentonite, compacted at a dry density of $1.7 \mathrm{Mg} / \mathrm{m}^{3}$. GMZ bentonite contains $75.4 \%$ Na-smectite (Ye et al. 2009). Figure 2 presents the variations of micro porosity and macro porosity with suction for GMZ bentonite calculated from Eqs. 5 and 6. Figure 2 presents a comparison of micro porosity with those for compacted MX-80 bentonite calculated by Sedighi and Thomas (2014) based on a geochemical modelling approach. The results are compatible with those presented for compacted MX-80. Both MX-80 and GMZ are sodium smectite-rich clays although, the smectite content of the GMZ bentonite is lower than that of the MX-80 bentonite. It can be observed that at saturation, $\phi_{\text {micro }}$ is approximately 2.6 times larger than that of $\phi_{\text {macro }}$ that accounts only for $27.9 \%$ of the total porosity. Substituting all variables and constants, the saturated hydraulic conductivity of compacted GMZ is found to be $1.01 \times 10^{-13}(\mathrm{~m} / \mathrm{s})$. The value obtained is very close to the value reported based on experimental tests (e.g. $1.18 \times 10^{-13}$ by Ye et al. (2009)). In this study we use van Genuchten's relationship between water content and suction (Van Genuchten 1980):

$$
\theta_{l}=\frac{\theta_{s a t}-\theta_{r}}{\left[1+(\alpha s)^{n}\right]^{(1-1 / n)}}
$$

where, $s$ is suction. $\alpha$ and $n$ are fitting parameters.

Figure 3 presents the variations of unsaturated hydraulic conductivity of compacted GMZ bentonite with total volumetric water content. The relative permeability is calculated using Eqs. 9 and 10 for comparison with experimental data presented by $\mathrm{Ye}$ et al. (2009). For both approaches the value of $\alpha$ is assumed to be 3 that is acceptable value across in the literature. The results obtained by using the proposed relationship for the relative permeability correlate well with the experimental data. In comparison with the classic approach that considers total volumetric water content/porosity, the new relationship provides a better correlation with the experimental results. 


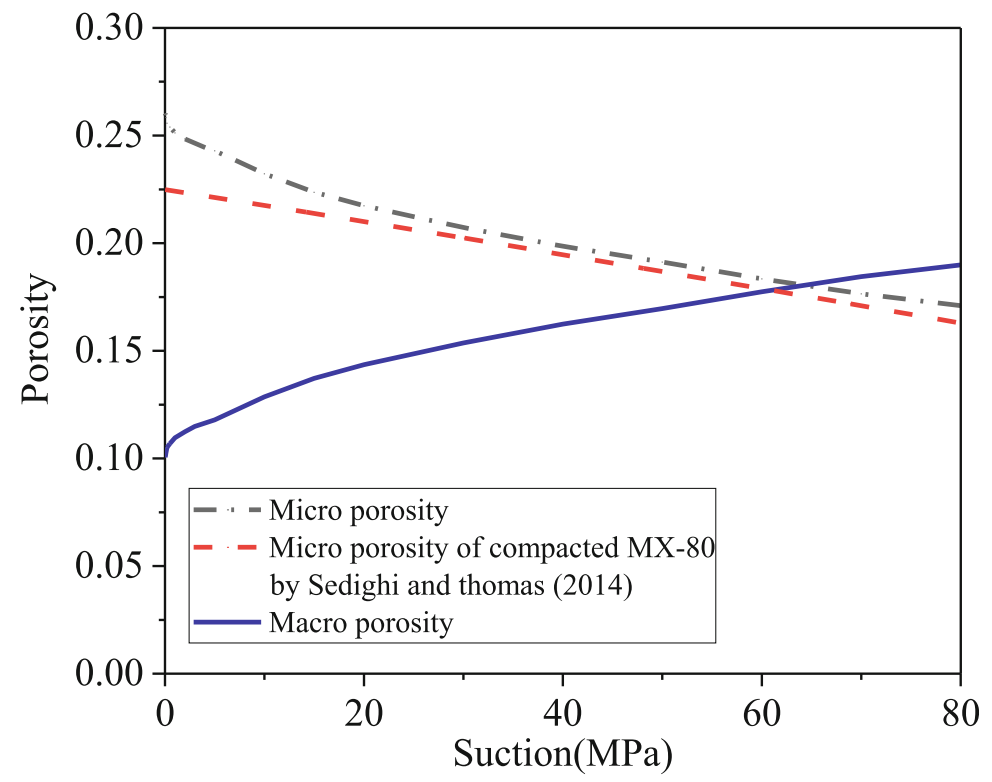

Fig. 2. Variations of micro and macro porosity of compacted bentonite with suction.

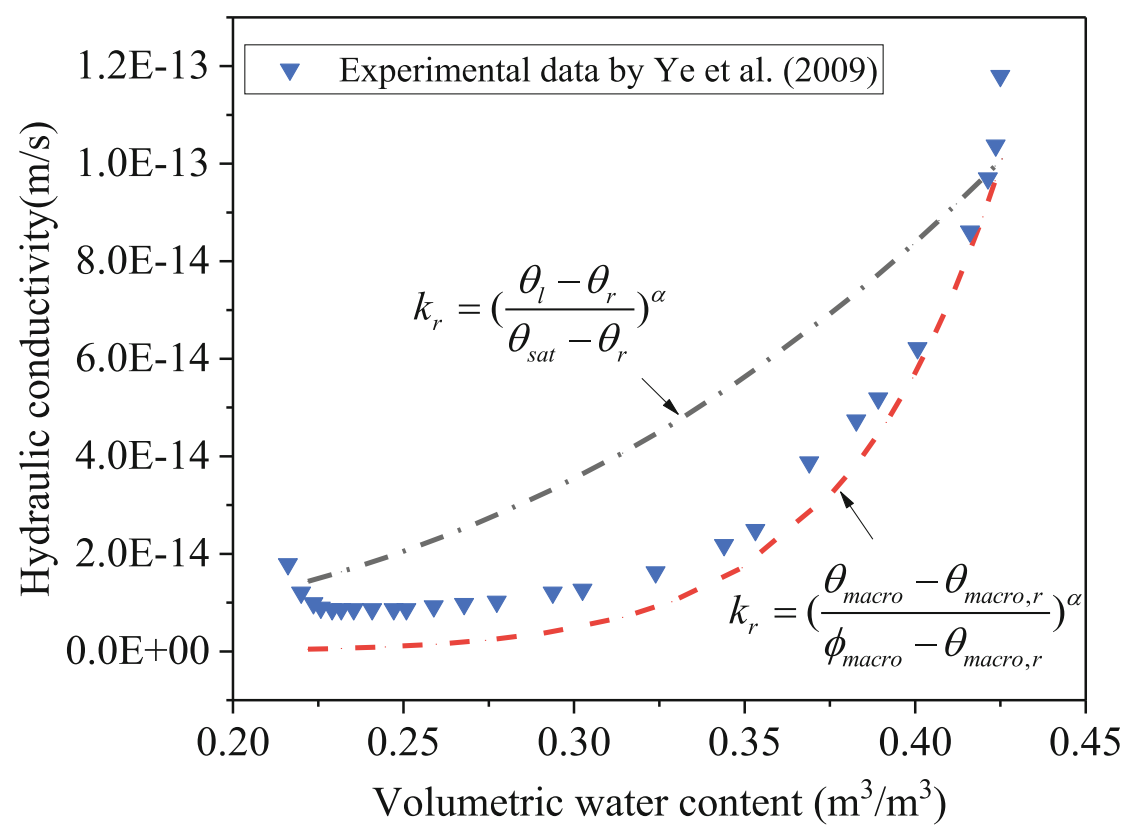

Fig. 3. Variation of unsaturated hydraulic conductivity of compacted GMZ with water content. 


\section{Conclusions}

A new approach for describing the effects of microstructure on hydraulic conductivity of compacted bentonite was presented. The Kozeny-Carman relationship was revisited to include the dual porosity system of compacted bentonite. It was shown that by using the revised relative permeability relationship proposed in this paper, an improved correlation with experimental data for the case of compacted GMZ bentonite is achieved. The new developments have important applications in predicting the flow behaviour of smectite rich clays in which a more accurate description of the pore system evolution is included.

Acknowledgements. Financial support through the University of Manchester's President Doctoral Scholarship Award for Tian Chen ( $1^{\text {st }}$ author $)$ is gratefully acknowledged.

\section{References}

Azizian S (2004) Kinetic models of sorption: a theoretical analysis. J Colloid Interface Sci 276 (1):47-52

Carman PC (1939) Permeability of saturated sands, soils and clays. J Agric Sci 29(2):262-273

Chapuis RP, Aubertin M (2003) On the use of the Kozeny-Carman equation to predict the hydraulic conductivity of soils. Can Geotech J 40(3):616-628

Holmboe M, Wold S, Jonsson M (2012) Porosity investigation of compacted bentonite using XRD profile modeling. J Contam Hydrol 128(1-4):19-32

Kozeny J (1927) Uber kapillare leitung der wasser in boden. R Acad Sci Vienna Proc Cl I 136:271-306

Mualem Y (1976) A new model for predicting the hydraulic conductivity of unsaturated porous media. Water Resour Res 12(3):513-522

Pusch R, Yong RN (2006) Microstructure of smectite clays and engineering performance. Taylor and Francis, New York

Saiyouri N, Tessier D, Hicher PY (2004) Experimental study of swelling in unsaturated compacted clays. Clay Miner 39(4):469-479

Sedighi M, Thomas HR, Vardon PJ (2012) On the reactive transport of chemicals in unsaturated expansive soils. In: The 4th international conference on problematic soils, Wuhan, China, pp 211-218

Sedighi M, Thomas HR (2014) Micro porosity evolution in compacted swelling clays - A chemical approach. Appl Clay Sci 101:608-618

Sedighi M, Thomas HR, Vardon PJ (2018) Reactive transport of chemical in compacted bentonite under nonisothermal water infirltration. J Geotech Geoenviornmental Eng ASCE (Accepted)

Van Genuchten MT (1980) A closed-form equation for predicting the hydraulic conductivity of unsaturated soils. Soil Sci Soc Am J 44(5):892-898

Villar M, Gómez-Espina R, Gutiérrez-Nebot L (2012) Basal spacings of smectite in compacted bentonite. Appl Clay Sci 65:95-105

Ye WM, Cui YJ, Qian LX, Chen B (2009) An experimental study of the water transfer through confined compacted GMZ bentonite. Eng Geol 108(3-4):169-176 